\title{
Identification and physiological characterization of phosphatidic acid phosphatase enzymes involved in triacylglycerol biosynthesis in Streptomyces coelicolor
}

Santiago Comba, Simón Menendez-Bravo, Ana Arabolaza* and Hugo Gramajo*

\begin{abstract}
Background: Phosphatidic acid phosphatase (PAP, EC 3.1.3.4) catalyzes the dephosphorylation of phosphatidate yielding diacylglycerol (DAG), the lipid precursor for triacylglycerol (TAG) biosynthesis. Despite the importance of PAP activity in TAG producing bacteria, studies to establish its role in lipid metabolism have been so far restricted only to eukaryotes. Considering the increasing interest of bacterial TAG as a potential source of raw material for biofuel production, we have focused our studies on the identification and physiological characterization of the putative PAP present in the TAG producing bacterium Streptomyces coelicolor.

Results: We have identified two S. coelicolor genes, named Ippa (SCO1102) and Ipp $\beta$ (SCO1753), encoding for functional PAP proteins. Both enzymes mediate, at least in part, the formation of DAG for neutral lipid biosynthesis. Heterologous expression of Ippa and Ipp $\beta$ genes in E. coli resulted in enhanced PAP activity in the membrane fractions of the recombinant strains and concomitantly in higher levels of DAG. In addition, the expression of these genes in yeast complemented the temperature-sensitive growth phenotype of the PAP deficient strain GHY58 (dpp1/pp1pah1). In S. coelicolor, disruption of either Ippa or Ipp $\beta$ had no effect on TAG accumulation; however, the simultaneous mutation of both genes provoked a drastic reduction in de novo TAG biosynthesis as well as in total TAG content. Consistently, overexpression of Lppa and $L p p \beta$ in the wild type strain of S. coelicolor led to a significant increase in TAG production.
\end{abstract}

Conclusions: The present study describes the identification of PAP enzymes in bacteria and provides further insights on the genetic basis for prokaryotic oiliness. Furthermore, this finding completes the whole set of enzymes required for de novo TAG biosynthesis pathway in S. coelicolor. Remarkably, the overexpression of these PAPs in Streptomyces bacteria contributes to a higher productivity of this single cell oil. Altogether, these results provide new elements and tools for future cell engineering for next-generation biofuels production.

Keywords: PAP, Triacylglycerol, Oleaginous bacteria, Lipid metabolism

\footnotetext{
* Correspondence: arabolaza@ibr-conicet.gov.ar; gramajo@ibr-conicet.gov.ar Microbiology Division, IBR (Instituto de Biología Molecular y Celular de Rosario), Consejo Nacional de Investigaciones Científicas y Técnicas. Facultad de Ciencias Bioquímicas y Farmacéuticas, Universidad Nacional de Rosario, Suipacha 531, S2002LRK, Rosario, Argentina
} 


\section{Background}

Triacylglycerols (TAG) are the most common lipid-based energy reserves in animals, plants, and eukaryotic microorganisms [1]. In bacteria, only a few examples of substantial TAG accumulation have been reported, mainly in members of the actinomycetes group of bacteria, such us Mycobacterium [2], Nocardia [3], Rhodococcus [4], and Streptomyces [5]. TAG biosynthesis occurs in nature by three different enzymatic activities: diacylglycerol: acyltransferase, phospholipid:diacylglycerol acyltransferase, and diacylglycerol:diacylglycerol acyltransferase [6-10]. These three reactions involve acylation of diacylglycerol (DAG), making this lipid a fundamental precursor of TAG biosynthesis. DAG moiety is produced by reactions that are partially shared with the glycerophospholipid biosynthesis pathway [11,12] (Figure 1), consisting in consecutive acylations of glycerol-3-phosphate (G3P), catalyzed by G3P:acyltransferase and lysophosphatidic acid (LPA) acyltransferase, generating phosphatidic acid (PA). PA can be dephosphorylated by the enzyme phosphatidic acid phosphatase (PAP) yielding DAG. Alternatively, PA is used for the synthesis of the liponucleotide intermediate CDP-DAG by the phosphatidate cytidylyltransferase enzyme [12]. Bacteria produce their membrane glycerophospholipids exclusively through CDP-DAG route, making PA the metabolic branch point dividing TAG and glycerophospholipid synthesis [13,14]. Thus, DAG formation is the first specific reaction of TAG biosynthesis in oleaginous bacteria, suggesting a key role of PAP activity in the regulation of PA flux towards TAG or glycerophospholipid synthesis [14] (Figure 1).

PAP enzymes (EC 3.1.3.4) have been identified and characterized in various eukaryotes. In yeast cells, PAP activity plays a central role in both lipid metabolism and intracellular signaling mechanisms $[15,16]$. Two distinct family of PAPs, referred to as PAP1 and PAP2, have been described [17-19]. The enzymes belonging to the PAP1 family show a $\mathrm{Mg}^{2+}$-dependent PAP activity, utilize PA as a unique substrate and localize in the soluble fraction of the cell [20-22]. In contrast, the PAP2 enzymes utilize an array of different substrates such as PA, LPA, sphingosine1- phosphate and diacylglycerol pyrophosphate (DGPP) among others. This family, currently known as lipid phosphate phosphatases LPPs, do not require $\mathrm{Mg}^{2+}$ for activity and are integral membrane proteins [23].

The first member of the PAP1 family of enzymes (Pah1) has been purified and characterized from the membrane and cytosolic fractions of yeast [24]. The analysis of mutants lacking the pah1 gene has provided evidences that this enzyme generates the DAG used for lipid synthesis [25]. Cells containing a pah1 mutation accumulate PA and have reduced amounts of DAG and its acylated derivative TAG [25]. The genes encoding for the PAP1 family of enzymes are highly conserved among eukaryotic species, but they do not possess any homologues in bacterial genomes.

On the other hand, the main PAP2 enzymes are encoded in yeast by the $d_{p p 1}$ [26] and $\operatorname{lpp} 1$ [27] genes,

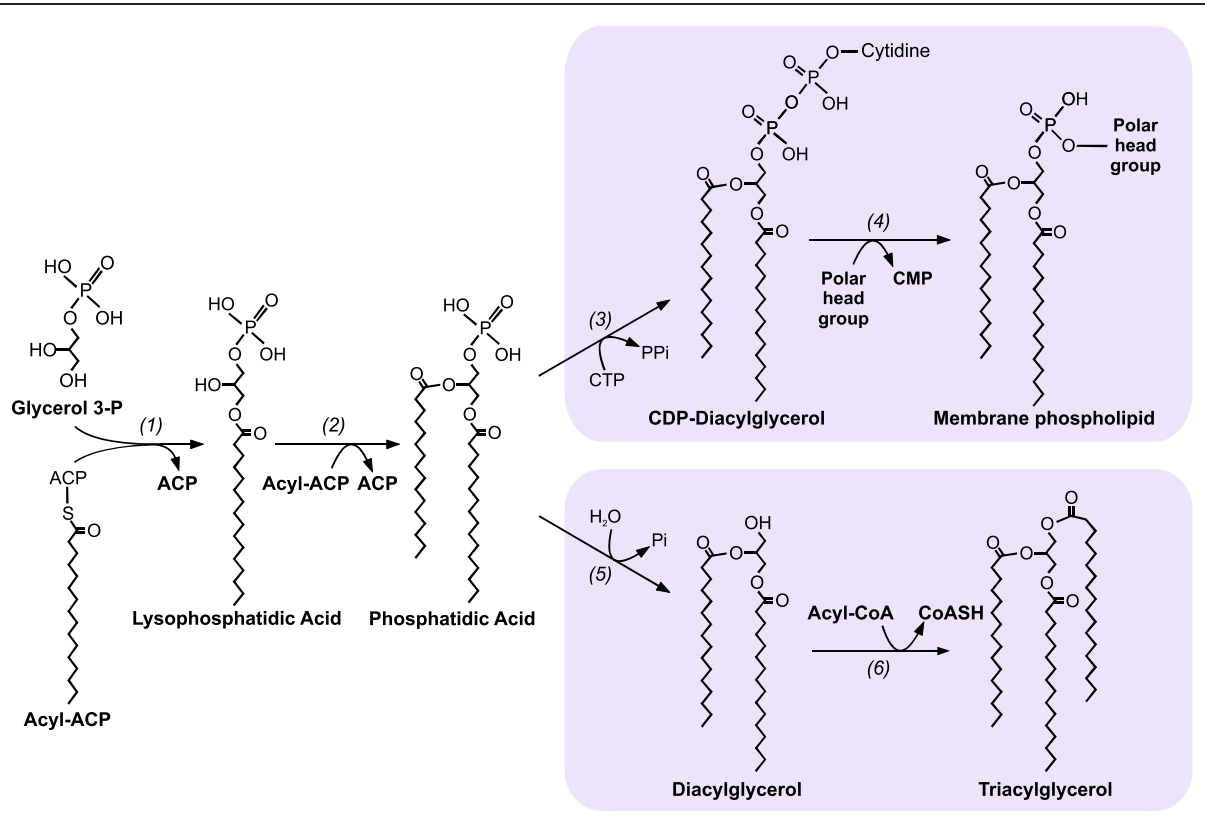

Figure 1 Biosynthesis of membrane glycerophospholipids and triacylglycerols in S. coelicolor. PA is the metabolic branch point dividing glycerophospholipid and triacylglycerol biosynthesis. (1) G3P:acyltransferase. (2) Lisophosphatidic acid acyltransferase. (3) Phosphatidate cytidylyltransferase. (4) Phosphatidyltransferase. (5) Phosphatic acid phosphatase. (6) Diacylglycerol:acyltransferase. 
with the former being the principal contributor of this activity [27]. The $d p p 1$ and $l p p 1$ gene products are integral membrane proteins with six transmembrane spanning regions and are localized in the vacuole $[28,29]$ and Golgi [30] compartments of the cell, respectively. The Dpp1 enzyme shows a preference for DGPP as a substrate [31], whereas the Lpp1 enzyme has similar substrate specificity for both PA and DGPP [32]. Overall, these enzymes belong to the PAP2 superfamily (pfam 01569), which includes more than 600 eukaryotic and prokaryotic proteins. Within the members of this group, PgpB of E. coli is the only enzyme known to display PAP activity [33]. Originally, $p g p B$ was identified in a screen designed to isolate cells defective in phosphatidylglycerol phosphate (PGP) phosphatase activity [34]. However, further analyses suggested that PgpB had a broad substrate spectrum, as demonstrated by its in vitro phosphatase activities towards PGP, PA, LPA, DGPP and undecaprenyl pyrophosphate (C55-PP) [33-36]. Touzé et al. reported that PgpB prefers pyrophosphate lipids as substrates and indicated that this enzyme is involved in the C55-P metabolism [35].

Interestingly within this superfamily, Nakamura et al., identified and characterized plastidic PAP2 enzymes in Arabidopsis thaliana (LPPs $\beta, \gamma, \delta, \varepsilon 1$ and $\varepsilon 2)$ and its homologue in Synechocystis sp. PCC6803 (synLPP) [37]. The author suggested that theses enzymes belong to a prokaryotic subfamily of PAP2 and could be involved in providing DAG precursors for monogalactosyl and digalactosyl diacylglycerol synthesis [37].

Remarkably, despite the functional relevance of these proteins in lipid metabolism of oleaginous bacteria, no studies were conducted towards the identification and characterization of PAPs in this group of bacteria. In an effort to unravel the biochemical properties and physiological significance of these proteins in S. coelicolor, we carried out a comprehensive bioinformatic analyses to identify and further characterize the PAP enzyme(s) of this microorganism. In this study we present the genetic and biochemical characterization of two Streptomyces PAPs, specifically demonstrating that SCO1102 (lpp $\alpha)$ and SCO1753 $(\operatorname{lpp} \beta)$ encode PAP enzymes catalyzing the formation of DAG from PA and that both proteins are essential for achieving wild type levels of TAG in this microorganism.

\section{Results and discussion}

\section{Identification of putative PAPs in S. coelicolor}

Analysis of the S. coelicolor genome with Pfam [38] and Conserved Domain Database [39] tools reveals that it encodes at least 14 proteins with putative PAP2 domains (pfam1569). As we already mentioned, this class of enzymes are involved in a myriad of reactions with different lipid phosphates as substrates. Thus, in order to identify the putative PAP enzymes responsible for DAG production, we performed an homology sequence search over the $S$. coelicolor genome database with the amino acid sequence of the synLPP protein as query, using BLAST [40] and FASTA [41] algorithms. FASTA analysis presented significant matches $\left(\mathrm{E}\right.$-value $<10^{-3}$ ) to Sco1102, Sco1753 and Sco6355 proteins, and the BLAST tool output also indicated these three proteins as the best hits. The three candidates were named Lpp $\alpha$ (Sco1102), Lpp $\beta$ (Sco1753) and Lppy (Sco6355) and have a predicted molecular weight of $24,8,37,8$ and $28,3 \mathrm{kDa}$, respectively. Detailed analysis of the protein sequences indicates that they conserve the key amino acids of the PAP2 catalytic domain and are all predicted to be integral membrane proteins [42] (Figure 2).

Phylogenetic analysis using curated sequences of LPPs from different organisms showed that $S$. coelicolor LPPs (scoLPPs) are evolutionary associated with synLPP, in the subgroup of prokaryotic LPPs (Figure 2). Non-plastidic LPPs of $A$. thaliana (atLPP $\alpha 1,2,3$ ) are clustered together with LPPs from human, murine and $S$. cerevisiae in a clade merely composed by eukaryotes LPPs (Figure 2). In agreement with Nakamura et al. [37], our studies also show that bacterial LPPs group closer to the clade of "plastidic LPPs with prokaryote origin" (atLPP $\delta, \varepsilon 1$ and $\varepsilon 2$ ) than to the eukaryotic one.

Additional bioinformatic analysis of these sequences revealed that scoLpp $\alpha$ (Sco1102) orthologues are conserved in all the available Streptomyces genomes, as well as in other species of actinomycetes belonging to the genus Mycobacterium, Rhodococcus and Nocardia, among others. The presence of scoLpp $\beta$ (Sco1753) homologous sequences is however limited to the Streptomyces genus, being present in all the species sequenced up to date. Finally, scoLppy (Sco6355) coding sequence is conserved only in S. coelicolor and in S. avermitilis. This gene is part of a five member operon (SCO6353-SCO6357) that also encodes for a putative sensor histidine kinase and a response regulator. The genome organization of scoLppy and the fact that this operon is absent in other actinomycetes, suggest a specific role of this protein in S. coelicolor and S. avermitilis metabolism.

Overall, orthologues sequences to scoLpp $\alpha$ and scoLpp $\beta$ are widely distributed among oleaginous bacteria, merely actinomycetes; thus these two proteins can be considered as the best PAP candidates.

\section{Heterologous expression of S. coelicolor Lppa, Lpp $\beta$ and Lppy in E. coli}

To initiate the functional characterization of $L p p \alpha, L p p \beta$ and Lppy, an N-terminal His-tag version of each gene was cloned under the control of $P_{B A D}$ promoter in the pBAD33 vector [43]. Plasmids pBAD-LPP $\alpha$, pBADL-LPP $\beta$ and $\mathrm{pBAD}-\mathrm{LPP} \gamma$ were introduced by transformation in E. coli C41 (DE) strain, which is suitable for overproduction of membrane proteins [44]. Transformed cells 
A

\begin{tabular}{|c|c|c|c|}
\hline & $\begin{array}{c}\text { Domain } 1 \\
\underline{K} \times x \times x \times x \underline{R}\end{array}$ & $\underset{\underline{\text { PSGH }}}{\operatorname{Domain}} 2$ & $\begin{array}{c}\text { Domain } 3 \\
\underline{R} \times x \times x \times \underline{H} \times x \times \mathbb{D}\end{array}$ \\
\hline & KAAVDRPRP & $\underline{\text { PSGH }}$ & RVWLGVHWATD \\
\hline SCOLPP $\beta$ & KYGMGRLGP & $\frac{\mathrm{PSGH}}{\mathrm{PSGH}}$ & TVYLGTHWLSD \\
\hline ScOLPPY & $\underline{\text { MALVARPRP }}$ & $\underline{\mathrm{PSGH}}$ & $\underline{R V Y L G V \underline{H} W F T \underline{D}}$ \\
\hline
\end{tabular}

B

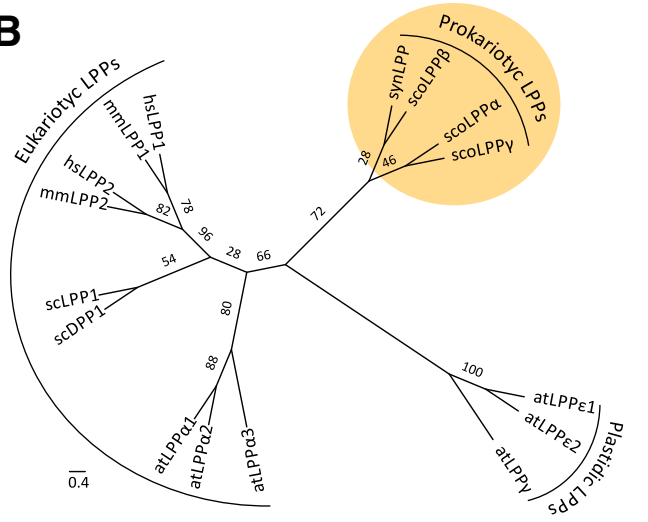

$\mathbf{C}$
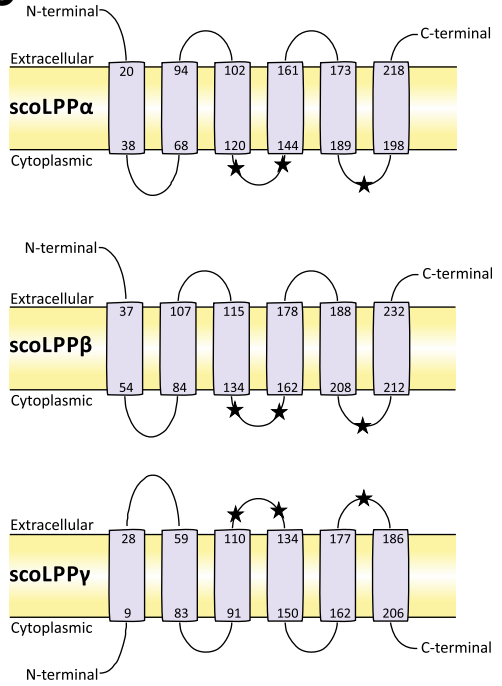

Figure 2 Bioinformatic analysis of S. coelicolor PAPs. (A) Sequence alignment of scoLPPs PAP2 domains. The key residues for this catalytic activity are underlined. (B) Phylogenetic tree of LPP enzymes from different organisms. Bootstrap values are shown along the branches. (C) Transmembrane topology prediction of scoLPPs. Numbers represent amino acid position of start and end of the respective transmembrane helix. Location of the catalytic domains is represented with black stars. Sequence accession numbers: atLPP_alfa1 [EMBL:Q9ZU49], atLPP_alfa2 [EMBL: Q9XI60], atLPP_alfa3 [EMBL:Q8LFD1], atLPP_epsilon1 [EMBL:F4J220], atLPP_epsilon2 [EMBL:Q6NQL6], atLPP_gamma [EMBL:Q6NLA5], scLPP1p [EMBL:Q04396], scDPP1p [EMBL:Q05521], hsLPP1 [EMBL:O14494], hsLPP2 [EMBL:O43688], mmLPP1 [EMBL:Q61469], mmLPP2 [EMBL:Q9DAX2], sCOLPPa [EMBL:Q9K3P6], scoLPPß [EMBL:Q9EWX3], scoLPPY [EMBL:O86624], synLPP [EMBL:Q55398].

were grown to mid-log phase and then cultivated for $16 \mathrm{~h}$ at $23^{\circ} \mathrm{C}$ after induction with L-arabinose. Immunoblot analysis of the corresponding E. coli soluble homogenates showed that each His-tagged protein migrated according to the molecular weight predicted for the polypeptides HisLpp $\alpha \quad(27 \mathrm{KDa})$, His-Lpp $\beta \quad(40 \mathrm{KDa})$ and His-Lppy $(30,5 \mathrm{kDa})$, respectively (Figure $3 \mathrm{~A})$. Then, we analyzed the total lipid profile of these recombinant strains by metabolic labeling with $\left[{ }^{14} \mathrm{C}\right]$-acetate. We found out that Lpp $\alpha$ and Lpp $\beta$ were able to raise the intracellular levels of DAG 3 to 6 -fold higher than that of the parental strain (Figure 3B). However, no modification in total lipid pattern, and particularly in DAG levels, was observed in the strain containing Lppy, suggesting either that this protein is not a functional PAP in this background or that it catalyzes a different reaction. The fatty acid content of cells expressing Lpp $\alpha$ and $\operatorname{Lpp} \beta$ was also increased when compared to the non-induced strains (Figure 3B). This effect could be due to an increased FA biosynthesis or to a higher recyclingdegradation of labeled lipids as a consequence of increasing DAG levels.

To evaluate $\mathrm{Mg}^{2+}$-independent PAP activity of the Streptomyces proteins, we used purified E. coli membrane homogenates of C41 (DE) strains expressing each of the three genes under study. As shown in Table 1, membrane proteins isolated from the strain expressing Lpp $\alpha$ and Lpp $\beta$ displayed a considerable increase in PAP activity compared with the control strain (C41 (DE) transformed with pBAD33). The highest difference was observed for Lpp $\beta$, with an increase of 5 -fold (Table 1). Cells expressing Lppy did not present difference in PAP activity relative to the control (Table 1).

\section{Lppa and $L p p \beta$ complement the temperature sensitive phenotype of dpp1/pp1pah1-deficient yeast cells}

To continue with the functional characterization of Lpp $\alpha$, Lpp $\beta$ and Lppy, each coding gene was linked to the constitutive GPD promoter in the yeast expression vector p425GPD [45]. The resulting constructs were transformed into S. cerevisiae GHY58 (dpp1lpp1pah1) mutant strain, which displays several phenotypes such as severe growth deficiency at $37^{\circ} \mathrm{C}$, reduced levels of PAP activity, elevated levels of PA and decreased levels of DAG and TAG [25]. Strains GHY58, GHY58/p425-LPP $\alpha$, GHY58/p425-LPP $\beta$, GHY58/p425-LPP $\gamma$, GHY58/p425GPD (control) and WH303-1A (wild type) were cultivated in YPD media during $48 \mathrm{~h}$ at $30^{\circ} \mathrm{C}$, normalized to $\mathrm{OD}_{600 \mathrm{~nm}} 1$ and serially diluted. The dilutions were plated on YPD media and then incubated at $37^{\circ} \mathrm{C}$ and $30^{\circ} \mathrm{C}$. We observed that strains GHY58/p425LPP $\alpha$ and GHY58/p425LPP $\beta$ incubated at $37^{\circ} \mathrm{C}$ displayed growth on dilutions as low as $1.0 \times 10^{-3}$ and $1.0 \times 10^{-1}$, respectively (Figure 4); while GHY58/p425GPD and cells expressing Lppy (GHY58/p425-LPP $)$ only grew, although poorly, at $\mathrm{OD}_{600} 1$ at $37^{\circ} \mathrm{C}$. At $30^{\circ} \mathrm{C}$ all cells lines presented comparable growth, indicating that complementation of temperature-sensitive phenotype resulted 


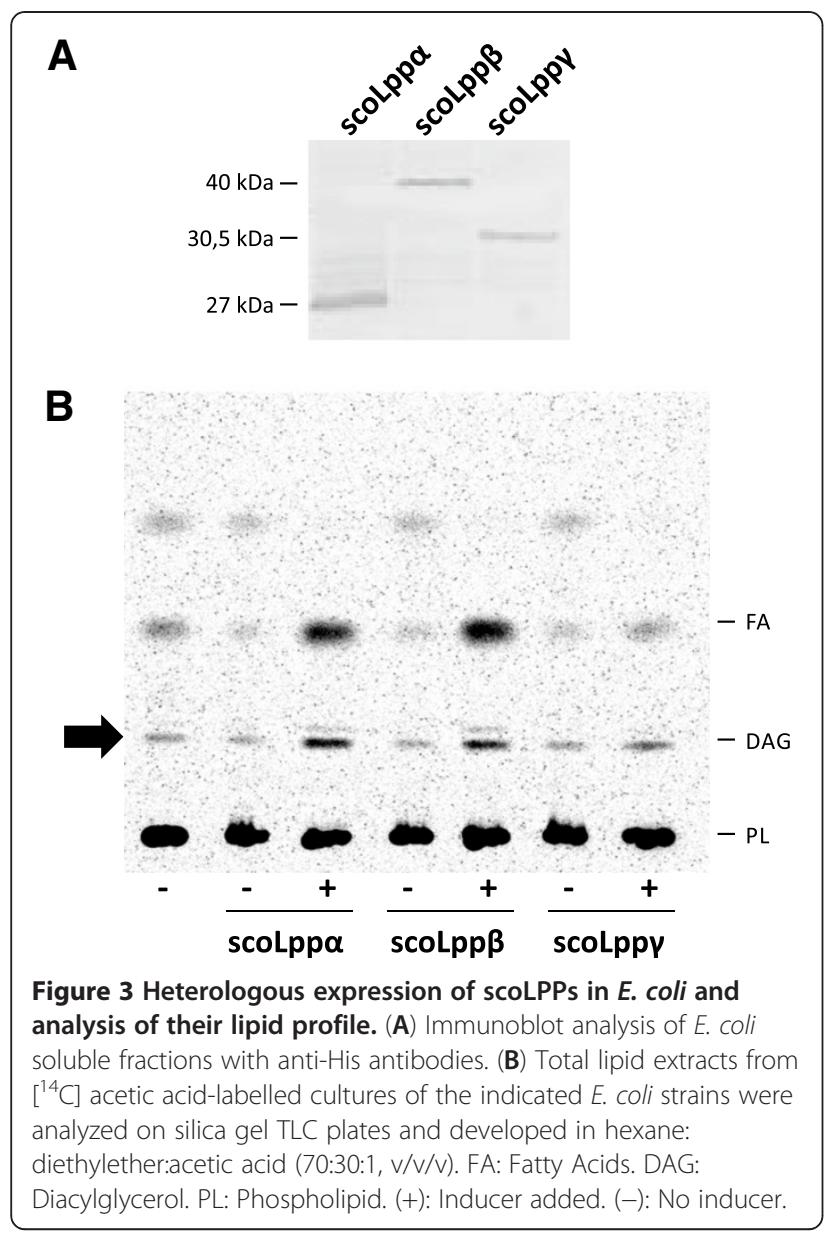

from Lppa and Lpp $\beta$ expression. As a control for plasmid maintenance, all the strains were plated on selective conditions (synthetic complete medium plus glucose $2 \%$ and omitting the corresponding amino acids). Furthermore, $\left[{ }^{14} \mathrm{C}\right]$-acetate labeling assays indicated that the expression of Lpp $\alpha$ and $L p p \beta$ in this mutant background increased the pools of DAG 3.2-fold and 2.2-fold respectively, relative to the wild type strain; while GHY58/ p425-LPP $\alpha$ and GHY58/p425-LPP $\beta$ did not restore the wild type levels of TAG (data not shown).

Since the heterologous expression of Lppy did not show a clear effect in lipid metabolism, neither in $E$. coli nor in $S$.

Table 1 Phosphatidic acid phosphatase activity in membranes of $E$. coli expressing scoLPPs

\begin{tabular}{|c|c|}
\hline Strain & Specific PAP activity \\
\hline $\mathrm{C} 41(\mathrm{DE} 3) / \mathrm{pBAD} 33$ & $0.9 \pm 0.2$ \\
\hline C41(DE3)/pBAD-LPPa & $2.51 \pm 0.06$ \\
\hline C41(DE3)/pBAD-LPP $\beta$ & $4.5 \pm 0.1$ \\
\hline C41(DE3)/pBAD-LPPY & $1.02 \pm 0.08$ \\
\hline
\end{tabular}

${ }^{a}$ Values represent the mean S.D. of triplicate determinations. cerevisiae, we continued the characterization of the other two S. coelicolor PAP candidates.

\section{Lppa and $L p p \beta$ are involved in TAG biosynthesis in $S$. coelicolor}

The in vivo role of $\mathrm{Lpp} \alpha$ and $\mathrm{Lpp} \beta$ in storage lipid synthesis was studied by generating single mutants in each of the genes encoding for the putative PAPs and also a double mutant strain. For this, each open reading frame was disrupted with a Tn5-derivative transposon (see Materials and Methods for details). TAG formation in the three mutant strains was analyzed by total lipid extraction and fractionation by normal-phase TLC. In all conditions tested, the single mutants did not show a significant effect on TAG accumulation (data not shown). However, in nitrogen-starving and carbon excess conditions (SMM media), where TAG synthesis is strongly induced, the lpp $\alpha$ lpp $\beta$ double mutant strain (SC_1153) presented a significant reduction in TAG content at exponential growth phase (Figure 5A). A densitometric quantification of each lipid type indicated that DAG content is about $30 \%$ lower than that of the wild type strain, while TAG content showed a reduction from $65 \%$ to $40 \%$ throughout growth compared with the M145 strain. Further analysis revealed a decrease of $28.2 \%$ in membrane-associated PAP activity of SC_1153 strain $(3.1 \pm 0.2 \mathrm{U} / \mathrm{mg})$, respect to the wild type strain $(4.29 \pm 0.09 \mathrm{U} / \mathrm{mg})$. The absence of phenotype in the single mutants suggests the existence of a compensating effect that can mitigate the disruption of the individual PAP enzymes. In this sense, expression of either Lpp $\alpha$ or Lpp $\beta$ in a SC_1153 genetic background was sufficient to restore TAG accumulation to wild type levels (data not shown). These results indicate that both genes products contribute to TAG biosynthesis in S. coelicolor and are necessary to achieve wild type levels of this storage compound, at least under the growth conditions tested. Moreover, the fact that the double mutant strain still produces considerable amounts of TAG also indicate that the remaining PAP activity present, as well as alternative pathway(s), can also generate the DAG needed for TAG biosynthesis in this strain.

To further evaluate the in vivo role of Lpp $\alpha$ and $\operatorname{Lpp} \beta$ in TAG biosynthesis, we constructed M145 derivative strains, each containing an extra copy of the Lpp $\alpha$ or the Lpp $\beta$ encoding genes under the transcriptional control of $P_{\text {ermE }}$ [46]. The strains were named SC_Lpp $\alpha$, SC_Lpp $\beta$ and SC_285 (control strain carrying the empty vector; Table 2). The recombinant strains were grown in different media and their ability to synthesize TAG was determined by total lipid extraction, TLC fractionation and densitometry quantification. Both SC_Lpp $\alpha$ and SC_Lpp $\beta$ strains reached lower cell density in liquid cultures of minimal SMM medium compared with the wild type strain, whereas timing of transition and stationary phase entrance 


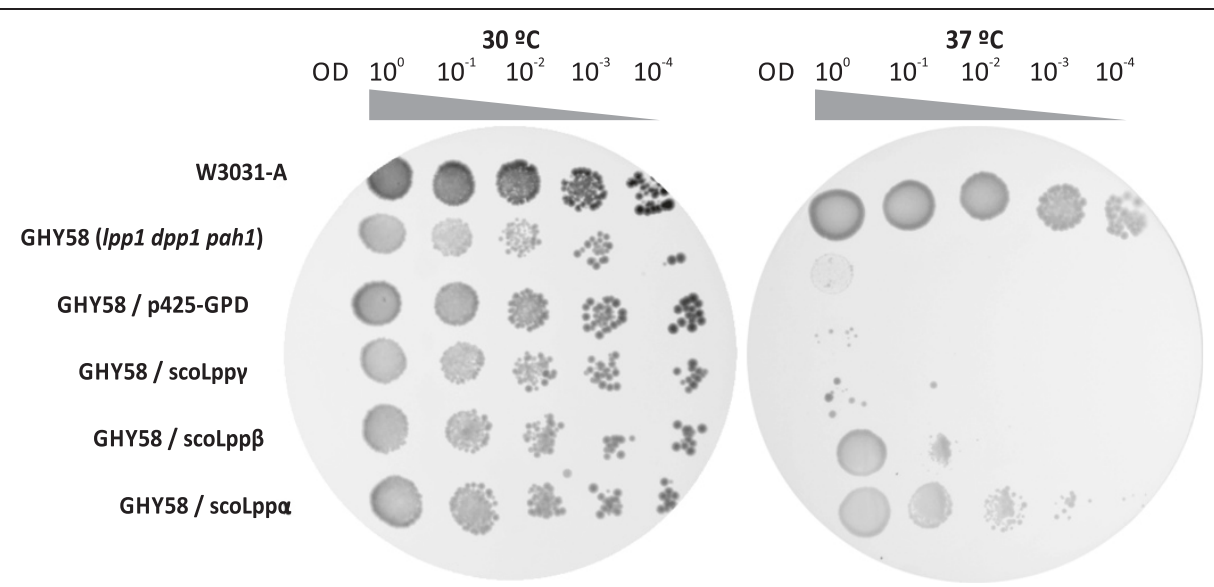

Figure 4 Complementation of the temperature sensitive phenotype of $d p p 1$ Ipp 1 pah1 yeast knockout strain by expressing scoLPPs. W3031A: wild type strain; GHY58 (Ipp 1dpp 1pah 1): triple knockout mutant strain; GHY58/p425GPD, GHY58/scoLppy, GHY58/scoLpp ß, GHY58/ scoLppa: triple knockout strain transformed with p425GPD empty vector and with P425GPD expressing scoLppy, scoLpp $\beta$ or scoLppa. $10 \mu l$ of each dilution were spotted on the plates, and followed by incubation at 30 and $37^{\circ} \mathrm{C}$ for two days.

was not affected (data no shown). This is not an unexpected observation, since overexpression of a PAP enzyme would shift the flux of PA to TAG, in detriment of glycerophospholipids synthesis; alternatively, by means of this reaction, DAG can be accumulated causing toxicity to the cell [47]. A third cause could be the merely effect of overexpressing a membrane protein. Therefore, although SMM medium is routinely used to analyze storage lipid content we had to conduct all these experiments in R5 rich media, where growth was less affected. As shown in Figure 5B, overexpression of LPPa caused an increase of $15.7 \%$ in the accumulation of TAG compared with the control strain at the early stationary phase of growth. Interestingly, lipid profile analysis of SC_Lpp $\beta$ overexpressing strain revealed an increase in the content of this neutral lipid, up to $29.9 \%$ compared with control strain, but in the late-stationary phase of growth (Figure 5B). Further, this effect was accompanied by a higher de novo TAG synthesis as determined by $\left[{ }^{14} \mathrm{C}\right]$-acetate labeling assays (data not shown).

These experiments are in agreement with the in vivo and in vitro studies mentioned before, and indicate that both Lpp $\alpha$ and Lpp $\beta$ are functional PAPs involved in TAG biosynthesis in S. coelicolor.

\section{Co-expression of S. coelicolor PAP and DGAT enzymes leads to TAG biosynthesis in $E$. coli}

In a previous work we reported that heterologuos expression of the DGAT (diacylglycerol:acyltransferase) Sco0958 from S. coelicolor in an E. coli dgk mutant, leads to the
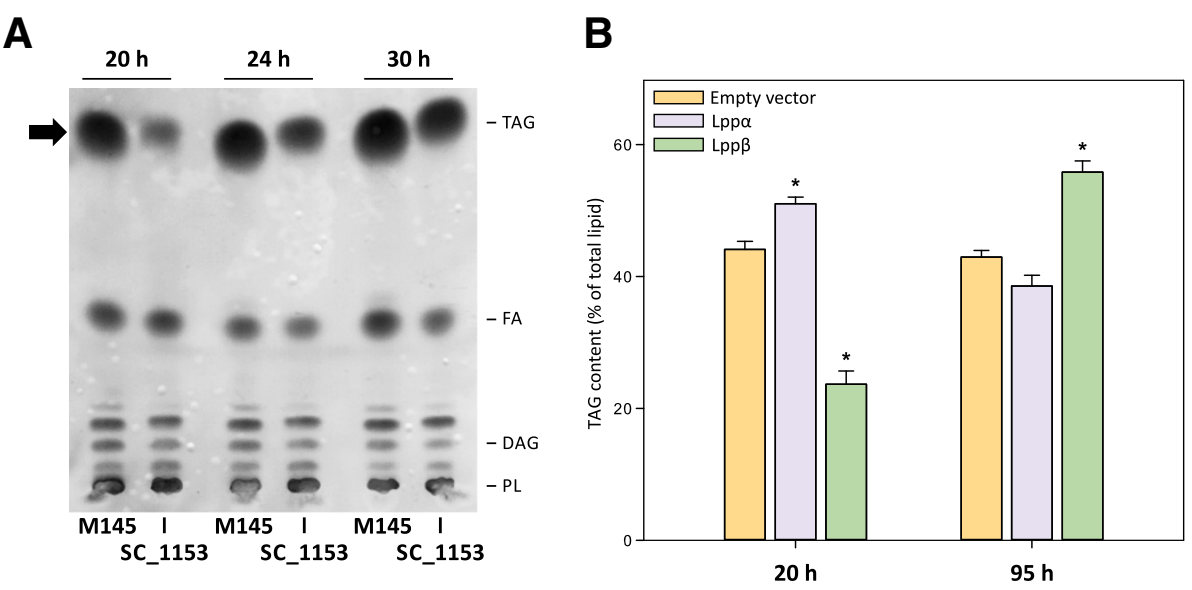

Figure 5 Analysis of the in vivo role of Lppa and Lpp $\beta$ in TAG accumulation. (A) Total lipid extracts from cultures of the indicated S. coelicolor strains grown on SMM medium during 20, 24 and 30 h, were analyzed on silica gel TLC plates and developed in hexane:diethylether: acetic acid $(70: 30: 1, v / v / v)$. (B) Quantification of TAG content of S. coelicolor strains overexpressing the indicated scoLPPs. Stars mean significant differences respect to empty plasmid control strain $(p<0.05)$. TAG: Triacylglycerol. FA: Fatty Acid. DAG: Diacylglycerol. PL: Phospholipid. 
Table 2 Strains and plasmids

\begin{tabular}{|c|c|c|}
\hline Strain or plasmid & Description & Reference \\
\hline \multicolumn{3}{|l|}{ Strains } \\
\hline \multicolumn{3}{|l|}{ S. coelicolor } \\
\hline M145 & Parental strain, $\mathrm{SCP} 1^{-} \mathrm{SCP} 2^{-}$ & [46] \\
\hline SC_1102 & SCO1102::Tn5062, derivative of M145; $\mathrm{Am}^{\mathrm{R}}$ & This study \\
\hline SC_1753 & SCO1753:: $\operatorname{Tn} 5062$, derivative of M145; $\mathrm{Am}^{\mathrm{R}}$ & This study \\
\hline SC_1153 & SCO1102::Tn5062 SCO1753::Tn5066, derivative of SC_1102; Am $^{R}$ Hyg $^{R}$ & This study \\
\hline SC_285 & M145 attB ФBT1:::pTR285; Km $_{\text {R }}$ & This study \\
\hline SC_Lppa & M145 attB $B_{\Phi B T 1:: \mathrm{p} 285-L P P a ; ~ K m^{R}}$ & This study \\
\hline SC_Lpp $\beta$ & M145 attB ${ }_{\Phi B T 1}:$ :p285-LPPß; Km ${ }^{R}$ & This study \\
\hline SC_P1102 & 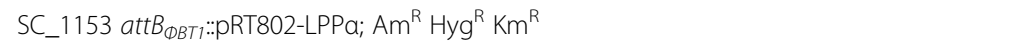 & This study \\
\hline SC_P1753 & SC_1153 attB $B_{\Phi B T 1}::$ RRT802-LPPB; Am $^{R}$ Hyg $^{R}$ Km $^{R}$ & This study \\
\hline \multicolumn{3}{|l|}{ E. coli } \\
\hline $\mathrm{DH} 5 \mathrm{a}$ & E. coli K12 F lacU169 (Ф80lacZ4M15) endA1 recA1 hsdR17 deoR supE44 thi-1 I2 gyrA96 relA1 & [48] \\
\hline BL21 (DE3) & $F^{-}$ompT gal dcm lon hsdS $S_{B}\left(r_{B}^{-} m_{B}^{-}\right) \lambda(D E 3)$ & Novagen \\
\hline C41 (DE3) & $F^{-}$ompT gal dcm lon hsdS $S_{B}\left(r_{B}^{-} m_{B}^{-}\right) \lambda(D E 3)$ & Lucigen \\
\hline ET 12567 & supE44 hsdS20 ara-14 proA2 lacY galK2 rpsL20 xyl5 $\mathrm{mtl}^{\top} 1 \mathrm{dam}^{-} \mathrm{dcm}-\mathrm{hsdM}^{-} \mathrm{Cm}^{\mathrm{R}}$ & [49] \\
\hline \multicolumn{3}{|l|}{ S. cerevisiae } \\
\hline W303-1A & MATa ade2-1 can1-100 his3-11,15 leu2-3,112 trp1-1 ura3-1 & [50] \\
\hline GHY58 & W303-1A dpp1_::TRP1/Kan ${ }^{R}$ Ipp1_::HIS3/Kan ${ }^{R}$ pah1_::URA3 & [25] \\
\hline \multicolumn{3}{|l|}{ Plasmids } \\
\hline pET28a & $\begin{array}{l}\text { Vector for expression of } \mathrm{N} \text { terminal His-tagged proteins under } \\
\text { the strong } \mathrm{T} 7 \text { promoter; } \mathrm{Km}^{\mathrm{R}}\end{array}$ & Novagen \\
\hline pBAD33 & Vector for recombinant protein expression under the control of the $P_{B A D}$ promoter; $\mathrm{Cm}^{\mathrm{R}}$ & [43] \\
\hline pCR ${ }^{\circledR}$-Bluntll-TOPO & Vector used for cloning of blunt PCR products; $\mathrm{Km}^{\mathrm{R}}$ & Invitrogen \\
\hline pUZ8002 & RK2 derivative with defective oriT; $\mathrm{Km}^{\mathrm{R}}$ & [49] \\
\hline pKOS111-47 & RK2 derivative with defective oriT; $A p^{R}$ & B. Julien (Personal communication) \\
\hline pQM5066 & Plasmid carrying a copy of $\operatorname{Tn} 5066$; Hyg $^{R}$ & P. Dyson, (Personal communication) \\
\hline pRT802 & Intregrative vector based on $\Phi \mathrm{BT} 1$ phage integrase; $\mathrm{Km}^{\mathrm{R}}$ & {$[51]$} \\
\hline p425GPD & Multicopy Yeast/E. coli expression vector with GPD promoter and LEU2 marker; Ap ${ }^{R}$ & [45] \\
\hline pTR285 & pRT802 derivative carrying the $P_{\text {ermE* }}$ promoter with no gene under its control; $\mathrm{Km}^{\mathrm{R}}$ & {$[52]$} \\
\hline pBAD0958 & pBAD33 carrying the $\mathrm{SCO} 0958^{\text {His }}$ gene under the control of $P_{B A D}$ promoter; $\mathrm{Cm}^{\mathrm{R}}$ & [52] \\
\hline PBAD-LPPa & pBAD33 carrying the $\mathrm{SCO} 1102^{\mathrm{His}}$ gene under the control of $P_{B A D}$ promoter; $\mathrm{Cm}^{\mathrm{R}}$ & This study \\
\hline PBAD-LPPß & pBAD33 carrying the $\mathrm{SCO} 1753^{\mathrm{His}}$ gene under the control of $P_{B A D}$ promoter; $\mathrm{Cm}^{\mathrm{R}}$ & This study \\
\hline PBAD-LPPY & pBAD33 carrying the $\mathrm{SCO} 6355^{\mathrm{His}}$ gene under the control of $P_{B A D}$ promoter; $\mathrm{Cm}^{\mathrm{R}}$ & This study \\
\hline p425-LPPa & p425-GPD carrying the SCO1102 ${ }^{\text {His }}$ gene under the control of GPD promoter; Ap ${ }^{R}$, LEU2 & This study \\
\hline P425-LPP $\beta$ & p425-GPD carrying the SCO1753 ${ }^{\text {His }}$ gene under the control of GPD promoter; Ap ${ }^{\mathrm{R}}$, LEU2 & This study \\
\hline p425-LPPy & p425-GPD carrying the SCO6355 ${ }^{\text {His }}$ gene under the control of GPD promoter; Ap ${ }^{R}$, LEU2 & This study \\
\hline p28-LPPa & pET28 carrying the $\mathrm{SCO} 1102^{\text {His }}$ gene under the control of T7 promoter; $\mathrm{Km}^{\mathrm{R}}$ & This study \\
\hline P28-LPPB & pET28 carrying the $\mathrm{SCO} 1753^{\mathrm{His}}$ gene under the control of T7 promoter; $\mathrm{Km}^{\mathrm{R}}$ & This study \\
\hline p285-LPPa & pTR285 carrying the $\mathrm{SCO} 1102^{\text {His }}$ gene under the control of $P_{\text {ermE* }}$ promoter; $\mathrm{Km}^{\mathrm{R}}$ & This study \\
\hline p285-LPP $\beta$ & pTR285 carrying the $\mathrm{SCO} 1753^{\text {His }}$ gene under the control of $P_{\text {ermE }}$ promoter; $\mathrm{Km}^{\mathrm{R}}$ & This study \\
\hline pRT802-LPPa & pRT802 carrying the $\mathrm{SCO} 1102^{\mathrm{His}}$ gene under the control of its own promoter; $\mathrm{Km}^{\mathrm{R}}$ & This study \\
\hline pRT802-LPP $\beta$ & pRT802 carrying the SCO1753 $3^{\text {His }}$ gene under the control of its own promoter; $\mathrm{Km}^{\mathrm{R}}$ & This study \\
\hline
\end{tabular}


accumulation of TAG in this host [52]. We employed a $d g k$ (diacylglycerol kinase) mutant strain because it presents higher levels of DAG than the wild type strain [52]; thus, this lipid could be used as substrate by the DGAT for TAG biosynthesis. In this sense, the single expression of Sco0958 in wild type $E$. coli did not generate detectable amounts of TAG [52]. To analyze whether we could reconstitute the complete $S$. coelicolor TAG biosynthesis pathway in $E$. coli, we co-expressed each of the identified PAPs Lppo or Lpp $\beta$ and the DGAT Sco0958. For this, we constructed a BL21 (DE3) derivative strain, where Sco0958 is expressed under the control of $P_{B A D}$ (pBAD0958, Table 2). The strain BL21/pBAD0958 was transformed with plasmids $\mathrm{p} 28$-LPP $\alpha$ or $\mathrm{p} 28$-LPP $\beta$, giving the strains BL21/pBAD0958/p28-LPP and BL21/ pBAD0958/p28-LPP $\beta$, respectively. Each recombinant strain was grown until mid-log phase and treated as described in Material and Methods. We found out that coexpression of either Lpp $\alpha$ or Lpp $\beta$ together with Sco0958 DGAT enzyme, led to TAG production in a wild type $E$. coli strain (Figure 6). These results clearly demonstrate that these enzymes are sufficient to synthesize de novo TAG using precursors from the glycerophospholipid metabolism of a non-oleaginous host.

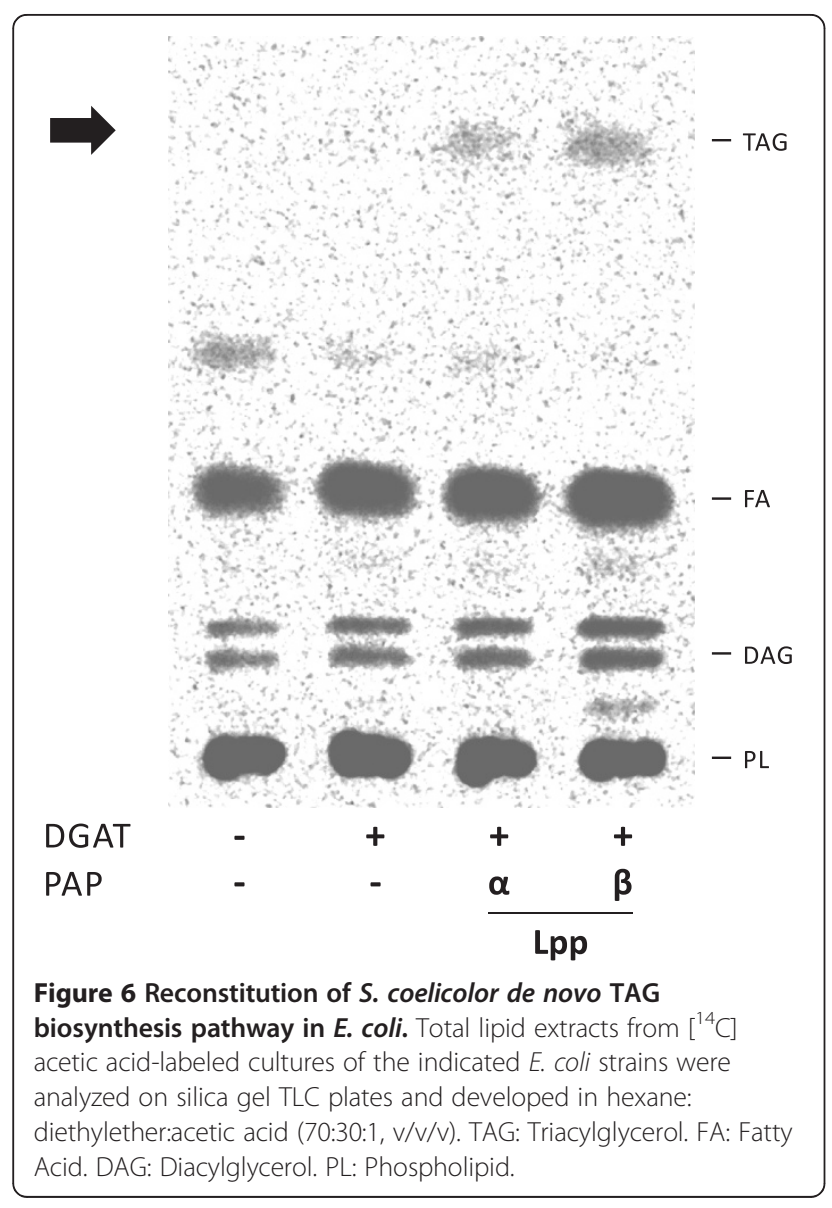

\section{Conclusions}

In this work we described the identification and physiological characterization of the first phosphatidic phosphatase enzymes involved in triacylglycerol biosynthesis in bacteria.

By means of a comprehensive bioinformatic analysis of the $S$. coelicolor genome, we were able to identify Lppo and Lpp $\beta$ as the best PAP candidates of this microorganism. They were both predicted to be integral membrane proteins belonging to the PAP2 family of enzymes also known as LPPs (pfam01569; Figure 2). Heterologous expression of $S$. coelicolor PAPs (scoLPPs) in E. coli increased the intracellular levels of DAG up to 6-fold and enhanced PAP activity in their membrane fractions up to 5-fold when compared with the control strain (Figure 3B, Table 1). Furthermore, when expressed in yeast, scoLPPs were able to complement the temperature sensitive phenotype of a $d p p 1 \operatorname{lpp} 1$ pah1 deficient mutant (Figure 4), and to raise the intracellular concentration of DAG.

To unravel the physiological role of Lpp $\alpha$ and Lpp $\beta$ in $S$. coelicolor, we constructed the corresponding simple and double mutant strains. Disruption of either lpp $\alpha$ or $\operatorname{lpp} \beta$ caused no alteration in the intracellular levels of TAG. However, inactivation of both genes, lpp $\alpha$ and $l p p \beta$, led to a clear reduction of the membrane associated PAP activity, as well as a reduction of TAG accumulation (Figure 5A). Further, overexpression of these genes in a wild type background provoked an increase of $15.7 \%$ and $29.9 \%$ in the content of TAG for Lpp $\alpha$ and Lpp $\beta$, respectively (Figure 5B). These observations support an active role of these two PAP enzymes in the TAG biosynthesis pathway of $S$. coelicolor.

Finally, co-expression of the $S$. coelicolor DGAT enzyme Sco0958 together with Lpp $\alpha$ or Lpp $\beta$ in E. coli reconstituted the complete pathway for de novo TAG biosynthesis in a heterologous host (Figure 6).

The identification of Lpp $\alpha$ and Lpp $\beta$ completes the minimal set of enzymes, together with the three DGATs previously characterized, required for de novo TAG biosynthesis in S. coelicolor. Remarkably, the overexpression of these PAPs in Streptomyces bacteria contributes to a higher productivity of this single cell oil.

Overall, these results provide new elements and tools for future cell engineering towards achieving sustainable and cost-effective single cell oil production in oleaginous bacteria. Furthermore, the successful reconstruction of the specific TAG biosynthesis pathway in a heterologous host with good fermentation properties such as $E$. coli broadens the bacterial platforms for next-generation biofuels production.

\section{Methods}

Strains, media and growth conditions

The strains and plasmids used in this study are described in Table 2. E. coli strains were grown either on solid or in 
liquid Luria-Bertani (LB) medium at $37^{\circ} \mathrm{C}$ and supplemented when needed with the following antibiotics: $100 \mu \mathrm{g} \mathrm{ml} l^{-1}$ ampicillin (Ap), $50 \mu \mathrm{g} \mathrm{ml}^{-1}$ kanamycin (Km), $20 \mu \mathrm{g} \mathrm{ml}{ }^{-1}$ chloramphenicol $(\mathrm{Cm}), 100 \mu \mathrm{g} \mathrm{ml}$ hygromycin (Hyg) or $50 \mu \mathrm{g} \mathrm{ml}^{-1}$ apramycin (Am). Yeast cells were grown in YPD medium (1\% yeast extract, $2 \%$ peptone, $2 \%$ glucose) or in synthetic complete (SC) medium containing $2 \%$ glucose at $30^{\circ} \mathrm{C}$ [53]. For selection of yeast cells bearing plasmids, appropriate amino acids were omitted from SC medium. Streptomyces strains were grown at $30^{\circ} \mathrm{C}$ in liquid media $\mathrm{R} 5$ or SMM and on solid media MS, R5, or in SMMS containing $1 \% \mathrm{w} / \mathrm{v}$ glucose (SMMS-glucose) [46]. The antibiotics Am, Hyg and Km were added at final concentrations of $50 \mathrm{\mu g} \mathrm{ml}^{-1}$ to solid medium respectively.

\section{Construction of Ippa and Ipp $\beta$ mutants and the Ippa Ipp $\beta$ double mutant strain of $S$. coelicolor}

Disruption of the open reading frames SCO1102 (lpp $\alpha)$ and SCO1753 $(\operatorname{lpp} \beta)$ was carried out by homologous recombination using cosmids from the transposon mutant ordered cosmid library of S. coelicolor [54]. Cosmids 6A05.2.b04 and I34.1.D02, carrying an individual Tn5062 insertion in SCO1102 and SCO1753 genes, respectively, were introduced into $S$. coelicolor M145 by conjugation using E. coli ET12567/pUZ8002 as donor. Three independent $\mathrm{Am}^{\mathrm{R}} \mathrm{Km}^{\mathrm{S}}$ exconjugants were isolated from each conjugation and checked by PCR, verifying that allelic replacement had occurred. The SCO1102 disruption was analyzed with 1102_F/R, 1102_F/EZL2, and 1102_R/ EZR1 primer pairs; and for the inactivation of SCO1753 oligonucleotides 1753_F/R, 1753_F/EZR1 and 1753_R/ EZL2 were used (Table 3).

In order to generate the double mutant strain, the Am resistance marker of cosmid I34.1.D02 was replaced by the Hyg resistance cassette of pQM5066 (P. Dyson,

\section{Table 3 Primers}

\begin{tabular}{lll}
\hline Name & Sequence (5'-3') & Reference \\
\hline EZR1 & ATGCGCTCCATCAAGAAGAG & {$[54]$} \\
EZL2 & TCCAGCTCGACCAGGATG & {$[54]$} \\
SCO1102_F & CCATATGCAGACGCCGCCGGTCGAC & This study \\
SCO1102_R & TGGCCGAATTCAAGGGGCGAAGGA & This study \\
SCO1753_F & CGATCATATGCGTACCGAACGGAAG & This study \\
SCO1753_R & CCCCGAATTCACCCGAACGACACC & This study \\
SCO6355_F & GGGTCATATGAAGCGCGGCGATGTC & This study \\
SCO6355_R & GTGAATTCCGGGGACGGTGTCGAAG & This study \\
P1102_F & GCGGCCGCCGACGGTGCCTTGTGG & This study \\
P1102_R & ACTAGTGGGGGCGAAGGATGCGACC & This study \\
P1753_F & GCGGCCGCGGGGTCGCGCTCCTGGT & This study \\
P1753_R & ACTAGTACCCGAACGACACCCCCTG & This study \\
\hline
\end{tabular}

Restriction sites are shown underlined. personal communication). Conjugal transfer of cosmid I34.1.D02 $\mathrm{Hyg}^{\mathrm{R}}$ to $\mathrm{SC} \_1102$ yielded $\mathrm{Am}^{\mathrm{R}} \mathrm{Hyg}^{\mathrm{R}} \mathrm{Km}^{\mathrm{S}}$ exconjugants. Three independent clones were picked and checked by PCR with the primer pairs described above for the mutations in SCO1102 and SCO1753.

\section{Cloning of Ippa, Ipp $\beta$ and Ippy genes}

lppa (SCO1102), lpp $\beta$ (SCO1753) and lppy (SCO6355) were amplified from S. coelicolor M145 genomic DNA by PCR with primers SCO1102_F/R, SCO1753_F/R and SCO6355_F/R, respectively. The resulting PCR products were cloned in $\mathrm{PCR}^{\circledR}$-BluntII-TOPO vector and checked by DNA sequencing. The DNA fragments containing $l p p \alpha, l p p \beta$ and lppy genes were cloned as NdeI/EcoRI digests in pET28a, to yield plasmids p28-LPP $\alpha$, p28-LPP $\beta$ and p28-LPPy. pET28 derivative plasmids containing each of the putative PAP sequences were digested with XbaI/ HindIII and the restriction fragments were cloned in the same sites of pBAD33, yielding pBAD-LPP $\alpha, \mathrm{pBAD}-\mathrm{LPP} \beta$, pBAD-LPP $\gamma$. In order to express PAP candidate genes in S. cerevisiae, the $\mathrm{XbaI} / \mathrm{HindIII}$ digestion fragments from the pET28 derivatives (p28-LPP $\alpha, \mathrm{p} 28-\mathrm{LPP} \beta, \mathrm{p} 28-\mathrm{LPP} \gamma$ ) were cloned in the SpeI/HindIII sites of $\mathrm{p} 425 \mathrm{GPD}$ vector, yielding $\mathrm{p} 425-\mathrm{LPP} \alpha, \mathrm{p} 425-\mathrm{LPP} \beta$ and $\mathrm{p} 425-\mathrm{LPP} \gamma$. To achieve overexpression of lpp $\alpha$ and $l p p \beta$ genes in $S$. coelicolor, the pET28 derivative plasmids containing these genes were digested with $\mathrm{XbaI} / \mathrm{HindIII}$ and the fragments were cloned in the SpeI/HindIII sites of pTR285 vector, yielding $\mathrm{p} 285-\mathrm{LPP} \alpha$ and $\mathrm{p} 285-\mathrm{LPP} \beta$.

To complement the S. coelicolor double mutant strain SC_1153, we amplified SCO1102 and SCO1753 genes plus 300 or 500 bp upstream sequences (in order to include the native promoter) with primers P1102_F/R and P1753_F/R, respectively. The resulting PCR products were cloned in $\mathrm{pCR}^{\circledR}$-BluntII-TOPO vector and checked by DNA sequencing. These sequences were cloned as NotI/SpeI digestion fragments in pRT802 vector, yielding plasmids pRT802-LPP $\alpha$ and pRT802-LPP $\beta$.

All the plasmids described in this section are listed in Table 2.

\section{Membrane preparation of $E$. coli and S. coelicolor strains}

E. coli $\mathrm{C} 41$ strains harbouring plasmid $\mathrm{pBAD}-\mathrm{LPP} \alpha, \mathrm{pBAD}-$ $\mathrm{LPP} \beta$ and $\mathrm{pBAD}-\mathrm{LPP} \gamma$ were grown in $\mathrm{LB}$ at $37^{\circ} \mathrm{C}$ until $\mathrm{OD}_{600 \mathrm{~nm}}$ 0.6. Then, protein expression was induced by addition of L-arabinose $0.2 \%$ and it was followed by overnight incubation at $23^{\circ} \mathrm{C}$ with gently shaking. Cells were harvested by centrifugation at $4,000 \times \mathrm{g}$ for $20 \mathrm{~min}$ at $4{ }^{\circ} \mathrm{C}$, washed twice with Buffer A (Tris- $\mathrm{HCl} \mathrm{pH} 7.550 \mathrm{mM}$, $\mathrm{NaCl} 100 \mathrm{mM}$, EDTA $1 \mathrm{mM}$, $\beta$-mercaptothanol $10 \mathrm{mM}$ ) and resuspended in the same buffer. The next steps were all done at $4{ }^{\circ} \mathrm{C}$. Disruption of the cells was carried out by sonication (Vibra-Cell ${ }^{\mathrm{TM}}$, Sonics \& Material Inc.), in the presence of $1 \mathrm{mM}$ phenylmethylsulfonyl fluoride 
(PMSF) and avoiding foaming. The lysate was cleared by centrifugation at $15,000 \times \mathrm{g}$ for $30 \mathrm{~min}$ to separate cell debris, and the supernatant was ultracentrifuged at $120,000 \times \mathrm{g}$ for $2 \mathrm{~h}$ to pellet the membrane fraction. The resulting pellet was washed twice with buffer $\mathrm{B}$ (Tris- $\mathrm{HCl}$ pH 7.5 $20 \mathrm{mM}, \beta$-mercaptothanol $10 \mathrm{mM}$, PMSF $0.5 \mathrm{mM}$ ), and resuspended in the same buffer. Protein concentration was quantified by Lowry assay using BSA as standard [55].

S. coelicolor strains were grown in the corresponding media indicated for each experiment. Cells were harvested by centrifugation at $4,000 \times \mathrm{g}$ for $20 \mathrm{~min}$ at $4{ }^{\circ} \mathrm{C}$ washed twice with Buffer $\mathrm{A}$ and resuspended in the same buffer. The next steps were done as described above for E. coli.

\section{SDS-PAGE and immunoblot}

SDS-PAGE and immunoblot analysis using nitrocellulose membranes were carried out using standard protocols [53,56]. For detection of the His-tagged proteins, mouse monoclonal anti-His antibodies (QIAGEN ${ }^{\mathrm{TM}}$ ) were used at a dilution of 1:1,000. Anti-mouse IgG-alkaline phosphatase conjugates were used as secondary antibodies at a dilution of 1:3,000. His-tagged proteins were visualized by immunoblots using chromogenic detection as described by the manufacturer.

\section{Phosphatidic acid phosphatase activity assay}

To test the phosphatase activity of the putative PAPs of $S$. coelicolor we used phosphatidic acid as the enzyme substrate. The diacylglycerol generated on the reaction was measured by LC-MS/MS. Standard phosphatase assays were performed in a $100 \mu \mathrm{L}$ reaction mixture containing $25 \mathrm{mM}$ Tris- $\mathrm{HCl}, \mathrm{pH}$ 7.5, $2.5 \mathrm{mM}$ Triton X-100 detergent and dipalmitoylphosphatidic acid (DPPA; Avanti Polar Lipids, Alabama, USA) $0.25 \mathrm{mM}$ as substrate. Aliquots of membrane fractions of the corresponding strain were added to initiate the reaction, and after incubation at $30^{\circ} \mathrm{C}$ the reactions were quenched by adding methanol:chloroform (2:1). Subsequent lipid extraction was performed by the addition of chloroform and distilled water. The organic phase was dried, solubilised in $50 \mu \mathrm{L}$ of mobile phase and $5 \mu \mathrm{L}$ aliquots were injected for HPLC and LC-MS/MS analysis. The organic extracts were separated on a ZORBAX Eclipse XDB-C8 column $(3.0 \times 50 \mathrm{~mm}$, particle size $=1.8 \mu \mathrm{m}$; Agilent, USA) using a binary solvent system of water (Solvent A) and methanol (Solvent B). A linear gradient from $80 \%$ B to $100 \%$ B was applied between 0 and 25 minutes. Both solvents were supplemented with $5 \mathrm{mM}$ ammonium acetate. The outlet of the liquid chromatograph was connected to a micrOTOF mass spectrometer (Bruker Daltonik, Bremen, Germany) operating in the positive-ion mode. The data was acquired online in the mass range $\mathrm{m} / \mathrm{z}$ 35-1000. Dipalmitoylglycerol (DPG) was detected as a the transition $\left[\mathrm{M}+\mathrm{NH}_{4}\right]^{+} \rightarrow[\mathrm{M}-\mathrm{R}-\mathrm{OH}]^{+}$ion $(\mathrm{m} / \mathrm{z} \quad 586.5 \rightarrow \mathrm{m} / \mathrm{z}$ 313.3). A calibration curve was done using DPG as standard (Avanti Polar Lipids, Alabama, USA), in the same conditions as the phosphatase reaction. DAG concentration in the samples was calculated by the linear regression equation obtained from the calibration curve.

A unit of enzymatic activity was defined as the amount of enzyme that catalyzed the formation of $1 \mathrm{nmol}$ of product $/ \mathrm{min}$. Specific activity was defined as units $/ \mathrm{mg}$ of protein. PAP activity was linear-dependent to time and protein concentration within the range tested.

\section{Total lipid analysis}

E. coli strains harboring $\mathrm{pBAD}-\mathrm{LPP} \alpha, \mathrm{pBAD}-\mathrm{LPP} \beta$ and $\mathrm{pBAD}-\mathrm{LPP} \gamma$ were grown in $\mathrm{LB}$ media at $37^{\circ} \mathrm{C}$ until $\mathrm{OD}_{600 \mathrm{~nm}}$ 0.6. Then, protein expression was induced by addition of L-arabinose $0.2 \%, 3 \mu \mathrm{Ci}\left[{ }^{14} \mathrm{C}\right]$-acetate was added at the same time and the culture was kept overnight at $23^{\circ} \mathrm{C}$. For Sco0958-PAPs co-expression experiment, cells at $\mathrm{OD}_{600 \mathrm{~nm}} 0.6$ were induced by $\mathrm{L}$-arabinose $0.2 \%$ and IPTG $0.1 \mathrm{mM} .3 \mu \mathrm{Ci}\left[{ }^{14} \mathrm{C}\right]$-acetate was added to the culture, and it was kept overnight at $23^{\circ} \mathrm{C}$. Total lipids of E. coli strains were extracted as described by Bligh \& Dyer [57] directly from ${ }^{14} \mathrm{C}$ labeled cells.

For S. coelicolor strains, total lipids were extracted twice from lyophilized cell material $(2 \mathrm{mg})$ with chloroform/ methanol $(2: 1 \mathrm{v} / \mathrm{v})$ as previously described [58]. For de novo lipid biosynthesis, S. coelicolor was grown in R5 liquid media and $3 \mathrm{ml}$ of culture was labeled for $3 \mathrm{~h}$ with $3 \mu \mathrm{Ci}$ $\left[{ }^{14} \mathrm{C}\right]$-acetate $(58.9 \mathrm{mCi} / \mathrm{mmol}$, PerkinElmer).

The lipid extracts were dried and analyzed by TLC on silica gel 60 F254 plates $(0 \pm 2 \mathrm{~mm}$, Merck), using the solvent systems hexane/diethylether/acetic acid (70:30:1, v/v/v) [59]. Lipid fractions were visualized by $\mathrm{Cu}$-phosphoric staining and identified by comparing to the mobility of known standards. For ${ }^{14} \mathrm{C}$ labeled lipids the radioactivity incorporated into each lipid fraction was quantified using a Storm 860 PhosphorImager (Molecular Dynamics) and the corresponding spots were quantified using ImageQuant software (version 5.2).

\section{Competing interests}

The authors declare that they have no competing interests.

\section{Authors' contributions}

SC, SMB, AA and HG designed all the experiments. SC did the sequences bioinformatic analysis and constructed the plasmid backbones. SC, SMB and AA performed all the experiments. AA and HG wrote the manuscript. All the authors read and approved the final manuscript.

\section{Acknowledgements}

We are grateful to Gustavo Millán for technical assistance with the LC-MS/MS experiments; to Gabriela Gago and Eduardo Rodriguez for helpful comments on the manuscript; and to Fundación Josefina Prats for a small grant to SC. We thank Gil-Soo Han and George M. Carman for kindly providing us the GHY58 yeast strain. This work was supported by ANPCyT Grants PICT2008-1640 and PICT 2011-2005. 
Received: 23 August 2012 Accepted: 20 January 2013

Published: 29 January 2013

\section{References}

1. Alvarez HM, Steinbuchel A: Triacylglycerols in prokaryotic microorganisms. Appl Microbiol Biotechnol 2002, 60:367-376.

2. Barksdale L, Kim KS: Mycobacterium. Bacterio/Rev 1977, 41:217-372.

3. Alvarez HM, Kalscheuer R, Steinbuchel A: Accumulation and mobilization of storage lipids by Rhodococcus opacus PD630 and Rhodococcus ruber NCIMB 40126. Appl Microbiol Biotechnol 2000, 54:218-223.

4. Alvarez HM, Mayer F, Fabritius D, Steinbuchel A: Formation of intracytoplasmic lipid inclusions by Rhodococcus opacus strain PD630. Arch Microbiol 1996, 165:377-386.

5. Olukoshi ER, Packter NM: Importance of stored triacylglycerols in Streptomyces: possible carbon source for antibiotics. Microbiology 1994, 140(Pt 4):931-943.

6. Liu Q, Siloto RM, Lehner R, Stone SJ, Weselake RJ: Acyl-CoA:diacylglycerol acyltransferase: molecular biology, biochemistry and biotechnology. Prog Lipid Res 2012, 51:350-377.

7. Kalscheuer R, Steinbuchel A: A novel bifunctional wax ester synthase/acylCoA:diacylglycerol acyltransferase mediates wax ester and triacylglycerol biosynthesis in Acinetobacter calcoaceticus ADP1. J Biol Chem 2003, 278:8075-8082.

8. Stahl U, Carlsson AS, Lenman M, Dahlqvist A, Huang B, Banas W, Banas A, Stymne $S$ : Cloning and functional characterization of a phospholipid:diacylglycerol acyltransferase from Arabidopsis. Plant Physiol 2004, 135:1324-1335.

9. Stobart K, Mancha M, Lenman M, Dahlqvist A, Stymne S: Triacylglycerols are synthesised and utilized by transacylation reactions in microsomal preparations of developing safflower (Carthamus tinctorius L.) seeds. Planta 1997, 203:58-66.

10. Fraser T, Waters A, Chatrattanakunchai S, Stobart K: Does triacylglycerol biosynthesis require diacylglycerol acyltransferase (DAGAT)? Biochemical Society Transactions 2000, 28:698-700.

11. Borkenhagen LF, Kennedy EP: The enzymatic synthesis of cytidine diphosphate choline. J Biol Chem 1957, 227:951-962.

12. Waltermann M, Stoveken T, Steinbuchel A: Key enzymes for biosynthesis of neutral lipid storage compounds in prokaryotes: properties, function and occurrence of wax ester synthases/acyl-CoA: diacylglycerol acyltransferases. Bio chimie 2007, 89:230-242.

13. Zhang YM, Rock CO: Membrane lipid homeostasis in bacteria. Nat Rev Microbiol 2008, 6:222-233.

14. Kalscheuer R: Genetics of Wax Ester and Triacylglycerol Biosynthesis in Bacteria. In Handbook of Hydrocarbon and Lipid Microbiology. Edited by KN T. Berlin Heidelberg: Springer; 2010.

15. Kocsis MG, Weselake RJ: Phosphatidate phosphatases of mammals, yeast and higher plants. Lipids 1996, 31:785-802.

16. Carman GM, Henry SA: Special issue: Regulation of lipid metabolism in yeast. Bio chim Biophys Acta 2007, 1771:239-240.

17. Carman GM, Han GS: Roles of phosphatidate phosphatase enzymes in lipid metabolism. Trends Biochem Sci 2006, 31:694-699.

18. Jamal Z, Martin A, Gomez-Munoz A, Hales P, Chang E, Russell JC, Brindley DN: Phosphatidate phosphohydrolases in liver, heart and adipose tissue of the JCR:LA corpulent rat and the lean genotypes: implications for glycerolipid synthesis and signal transduction. Int J Obes Relat Metab Disord 1992, 16:789-799.

19. Carrasco S, Merida I: Diacylglycerol, when simplicity becomes complex. Trends Biochem Sci 2007, 32:27-36.

20. Reue K, Brindley DN: Thematic Review Series: Glycerolipids. Multiple roles for lipins/phosphatidate phosphatase enzymes in lipid metabolism. J Lipid Res 2008, 49:2493-2503.

21. Donkor J, Zhang P, Wong S, O'Loughlin L, Dewald J, Kok BP, Brindley DN, Reue K: A conserved serine residue is required for the phosphatidate phosphatase activity but not the transcriptional coactivator functions of lipin-1 and lipin-2. J Biol Chem 2009, 284:29968-29978.

22. Han GS, Carman GM: Characterization of the human LPIN1-encoded phosphatidate phosphatase isoforms. J Biol Chem 2010, 285:14628-14638.

23. Brindley DN, Pilquil C: Lipid phosphate phosphatases and signaling. J Lipid Res 2009, 50(Suppl):S225-S230
24. Carman GM: Phosphatidate phosphatases and diacylglycerol pyrophosphate phosphatases in Saccharomyces cerevisiae and Escherichia coli. Biochim Biophys Acta 1997, 1348:45-55.

25. Han GS, Wu WI, Carman GM: The Saccharomyces cerevisiae Lipin homolog is a Mg2 +-dependent phosphatidate phosphatase enzyme. J Biol Chem 2006, 281:9210-9218.

26. Toke DA, Bennett WL, Dillon DA, Wu WI, Chen X, Ostrander DB, Oshiro J, Cremesti A, Voelker DR, Fischl AS, Carman GM: Isolation and characterization of the Saccharomyces cerevisiae DPP1 gene encoding diacylglycerol pyrophosphate phosphatase. J Biol Chem 1998, 273:3278-3284.

27. Toke DA, Bennett WL, Oshiro J, Wu WI, Voelker DR, Carman GM: Isolation and characterization of the Saccharomyces cerevisiae LPP1 gene encoding a Mg2 + -independent phosphatidate phosphatase. J Biol Chem 1998, 273:14331-14338.

28. Han GS, Johnston CN, Chen X, Athenstaedt K, Daum G, Carman GM: Regulation of the Saccharomyces cerevisiae DPP1-encoded diacylglycerol pyrophosphate phosphatase by zinc. J Biol Chem 2001, 276:10126-10133.

29. Han GS, Johnston CN, Carman GM: Vacuole membrane topography of the DPP1-encoded diacylglycerol pyrophosphate phosphatase catalytic site from Saccharomyces cerevisiae. J Biol Chem 2004, 279:5338-5345.

30. Huh WK, Falvo JV, Gerke LC, Carroll AS, Howson RW, Weissman JS, O'Shea EK: Global analysis of protein localization in budding yeast. Nature 2003, 425:686-691.

31. Wu WI, Liu Y, Riedel B, Wissing JB, Fischl AS, Carman GM: Purification and characterization of diacylglycerol pyrophosphate phosphatase from Saccharomyces cerevisiae. J Biol Chem 1996, 271:1868-1876.

32. Furneisen JM, Carman GM: Enzymological properties of the LPP1-encoded lipid phosphatase from Saccharomyces cerevisiae. Bio chim Biophys Acta 2000, 1484:71-82

33. Dillon DA, Wu WI, Riedel B, Wissing JB, Dowhan W, Carman GM: The Escherichia coli pgpB gene encodes for a diacylglycerol pyrophosphate phosphatase activity. J Biol Chem 1996, 271:30548-30553.

34. Icho T, Raetz CR: Multiple genes for membrane-bound phosphatases in Escherichia coli and their action on phospholipid precursors. J Bacteriol 1983, 153:722-730.

35. Touze T, Blanot D, Mengin-Lecreulx D: Substrate specificity and membrane topology of Escherichia coli PgpB, an undecaprenyl pyrophosphate phosphatase. J Biol Chem 2008, 283:16573-16583.

36. Lu YH, Guan Z, Zhao J, Raetz CR: Three phosphatidylglycerol-phosphate phosphatases in the inner membrane of Escherichia coli. J Biol Chem 2011, 286:5506-5518.

37. Nakamura Y, Tsuchiya M, Ohta H: Plastidic phosphatidic acid phosphatases identified in a distinct subfamily of lipid phosphate phosphatases with prokaryotic origin. J Biol Chem 2007, 282:29013-29021.

38. Punta M, Coggill PC, Eberhardt RY, Mistry J, Tate J, Boursnell C, Pang N, Forslund K, Ceric G, Clements J, et al: The Pfam protein families database. Nucleic Acids Res 2012, 40:D290-D301

39. Marchler-Bauer A, Lu S, Anderson JB, Chitsaz F, Derbyshire MK, DeWeeseScott C, Fong JH, Geer LY, Geer RC, Gonzales NR, et al: CDD: a Conserved Domain Database for the functional annotation of proteins. Nucleic Acids Res 2011, 39:D225-D229.

40. BLAST: Basic Local Alignment Search Tool [http://www.ncbi.nlm.nih.gov/BLAST/ ]

41. FASTA/SSEARCH/GGSEARCH/GLSEARCH - Protein Similarity Search [http:// www.ebi.ac.uk/Tools/sss/fasta/]

42. Nugent T, Jones DT: Transmembrane protein topology prediction using support vector machines. BMC Bioinformatics 2009, 10:159.

43. Guzman LM, Belin D, Carson MJ, Beckwith J: Tight regulation, modulation, and high-level expression by vectors containing the arabinose PBAD promoter. J Bacteriol 1995, 177:4121-4130.

44. Wagner S, Klepsch MM, Schlegel S, Appel A, Draheim R, Tarry M, Hogbom M, van Wijk KJ, Slotboom DJ, Persson JO, de Gier JW: Tuning Escherichia coli for membrane protein overexpression. Proc Natl Acad Sci U S A 2008, 105:14371-14376.

45. Mumberg D, Muller R, Funk M: Yeast vectors for the controlled expression of heterologous proteins in different genetic backgrounds. Gene 1995 156:119-122.

46. Kieser T, Bibb M, Buttner MJ, Chater KF, Hopwood DA: Practical Streptomyces genetics. Norwich, United Kingdom: The John Innes Foundation; 2000. 
47. Zavaleta-Pastor M, Sohlenkamp C, Gao JL, Guan Z, Zaheer R, Finan TM, Raetz CR, Lopez-Lara IM, Geiger O: Sinorhizobium meliloti phospholipase $\mathrm{C}$ required for lipid remodeling during phosphorus limitation. Proc Natl Acad Sci U S A 2010, 107:302-307.

48. Hanahan D: Studies on transformation of Escherichia coli with plasmids. J Mol Biol 1983, 166:557-580

49. Paget MS, Leibovitz E, Buttner MJ: A putative two-component signal transduction system regulates sigmaE, a sigma factor required for normal cell wall integrity in Streptomyces coelicolor A3(2). Mol Microbiol 1999, 33:97-107.

50. Thomas BJ, Rothstein $R$ : Elevated recombination rates in transcriptionally active DNA. Cell 1989, 56:619-630.

51. Gregory MA, Till R, Smith MC: Integration site for Streptomyces phage phiBT1 and development of site-specific integrating vectors. J Bacteriol 2003, 185:5320-5323.

52. Arabolaza A, Rodriguez E, Altabe S, Alvarez H, Gramajo H: Multiple pathways for triacylglycerol biosynthesis in Streptomyces coelicolor. Appl Environ Microbiol 2008, 74:2573-2582.

53. Sambrock J, Fritsch FEF, Maniatis T: Molecular cloning: a laboratory manual. Cold Spring Harbor, N. Y.: Cold Spring Harbor Laboratory Press; 1989.

54. Bishop A, Fielding S, Dyson P, Herron P: Systematic insertional mutagenesis of a streptomycete genome: a link between osmoadaptation and antibiotic production. Genome Res 2004, 14:893-900.

55. Lowry OH, Rosebrough NJ, Farr AL, Randall RJ: Protein measurement with the Folin phenol reagent. J Biol Chem 1951, 193:265-275.

56. Laemmli UK: Cleavage of structural proteins during the assembly of the head of bacteriophage T4. Nature 1970, 227:680-685.

57. Bligh EG, Dyer WJ: A rapid method of total lipid extraction and purification. Can J Biochem Physiol 1959, 37:911-917.

58. Arabolaza A, D'Angelo M, Comba S, Gramajo H: FasR, a novel class of transcriptional regulator, governs the activation of fatty acid biosynthesis genes in Streptomyces coelicolor. Mol Microbiol 2010, 78:47-63.

59. Rotering $\mathrm{H}$, Raetz CR: Appearance of monoglyceride and triglyceride in the cell envelope of Escherichia coli mutants defective in diglyceride kinase. J Biol Chem 1983, 258:8068-8073.

doi:10.1186/1475-2859-12-9

Cite this article as: Comba et al.: Identification and physiological characterization of phosphatidic acid phosphatase enzymes involved in triacylglycerol biosynthesis in Streptomyces coelicolor. Microbial Cell Factories 2013 12:9.

\section{Submit your next manuscript to BioMed Central and take full advantage of:}

- Convenient online submission

- Thorough peer review

- No space constraints or color figure charges

- Immediate publication on acceptance

- Inclusion in PubMed, CAS, Scopus and Google Scholar

- Research which is freely available for redistribution 